\title{
Successful lung cancer screening more than just scanning persons at risk
}

Second in incidence behind breast cancer, lung cancer causes by far the highest death toll worldwide. Recent progress in systemic treatment with the introduction of targeted therapy and immunotherapy lead to encouraging improvement in long term survival. However, the overall prognosis remains still poor. This can be attributed to the fact, that lung cancer remains clinically silent for a long period of time and is therefore diagnosed at advanced stages which limits the curative options. Cigarette smoking is accountable for $80-90 \%$ of all lung cancers and it is estimated that more than one in five adults in the world smoke tobacco. These two aspects advocate for two streams of lung cancer prevention: (I) primary prevention with smoking prevention and cessation and (II) secondary prevention with early disease detection through low dose chest computed tomography.

Evidence from randomized controlled trails could prove that low-dose chest CT based screening of patients at risk is able to reduce lung cancer related mortality. This led to the recommendation for lung cancer screening with low dose CT in the United States. Individuals are enrolled in the program based on their smoking history and age. Still, the optimal selection of screening candidates is a matter of debate. Recently the United States Preventive Task Force adapted the eligibility criteria for screening from $\geq 30$ to $\geq 20 \mathrm{PY}$ as it became obvious that current smokers of 20-29 PY have a similar risk compared to former smokers of $\geq 30 \mathrm{PY}$ who quit smoking within 15 years (a second eligibility criterium for screening). In his contribution to this series, Pilz discusses in more detail how to enhance the selection of a screening population based on independent risk factors integrated into a risk model. This might be a way to increase the effectiveness of a lung cancer screening program. Lung cancer screening CTs are currently conducted on an annual basis in the US. This adds an additional burden to the radiologists and requires an accurate longitudinal measurement of lesions if follow-up CTs, e.g., after 3 months were conducted to catch the lesion's growth dynamic. Measurements of small pulmonary nodules therefore must be highly accurate to avoid wrong conclusions. In their work, Sartorio and colleagues discuss the value of volumetric measurements compared to diameter as an option to increase the precision of nodule measurement as a prerequisite for follow-up. In addition to semiautomated volume measurement, it is reported by Yang et al. in this series, that new tools such as radiomics or neural network based deep learning approaches will help to increase the accuracy of classification. This will improve risk stratification of lung nodules detected by screening. Once a lung nodule is detected and the indication for a biopsy is set, the impact of underlying tumor heterogeneity on the efficacy of a core needle biopsy to allow a histopathological and molecular diagnostic characterization of a tumor needs to be considered. As an important contribution to this lung cancer screening series, the chance of detecting different histopathological and molecular features from a tumor specimen gained by a core needle biopsy is discussed by Binder $e t$ al.

As lung cancer screening is conducted as serial chest CT examinations e.g., on an annual basis, the aspect of cumulative radiation dose exposure is of high relevance. Several techniques have been developed to reduce the dose exposure to the patient and one of these-namely iterative reconstruction is discussed by Köng et al. in this series.

We know through other screening programs that screening can cause psychological distress. Apparently, it is important to consider psychological factors associated with lung cancer screening as well. In their work, Garcia et al. discuss the impact of false positive findings or indeterminate nodules and stigmatization of the individual by screening for lung cancer.

This special series in Shanghai Chest on lung cancer screening provides insights form renowned experts in their field to important aspects of lung cancer screening going beyond just scanning persons at risk.

\section{Acknowledgments}

Funding: None.

\section{Footnote}

Provenance and Peer Review: This article was commissioned by the editorial office, Shanghai Chest for the series "Lung Cancer Screening". The article did not undergo external peer review.

Conflicts of Interest: Both authors have completed the ICMJE uniform disclosure form (available at https://dx.doi. org/10.21037/shc-2021-03). The series "Lung Cancer Screening" was commissioned by the editorial office without any 
funding or sponsorship. Dr. Voigt and Dr. Prosch served as the unpaid Guest Editors of the series. Dr. Voigt is a former employee of Siemens Healthineers. He left the company in 2018. In the past 36 months, Dr. Prosch has received a research grant from Boehringer Ingelheim and has received honoraria from AstraZeneca, BMS, Boehringer Ingelheim, Chiesi, GE Healthcare, Lilly, MSD, Novartis, Roche/Intermune, Siemens, and he has received support for attending meetings and/or travel from Boehringer Ingelheim, Roche. The authors have no other conflicts of interest to declare.

Ethical Statement: The authors are accountable for all aspects of the work in ensuring that questions related to the accuracy or integrity of any part of the work are appropriately investigated and resolved.

Open Access Statement: This is an Open Access article distributed in accordance with the Creative Commons AttributionNonCommercial-NoDerivs 4.0 International License (CC BY-NC-ND 4.0), which permits the non-commercial replication and distribution of the article with the strict proviso that no changes or edits are made and the original work is properly cited (including links to both the formal publication through the relevant DOI and the license). See: https://creativecommons.org/licenses/by-nc$\mathrm{nd} / 4.0 \%$.

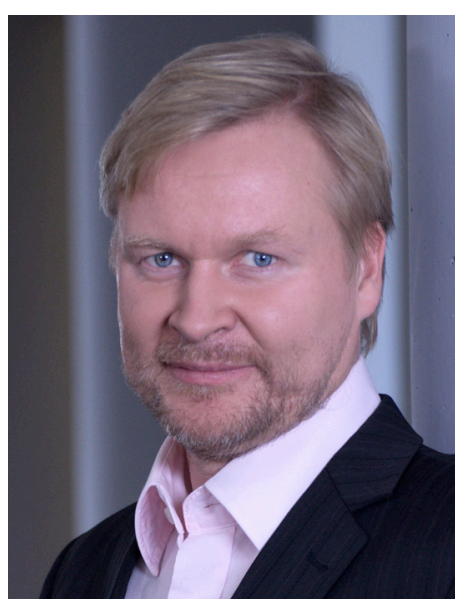

Wieland Voigt

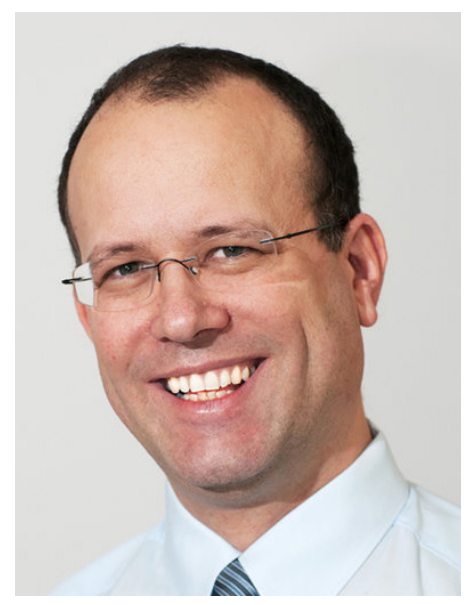

Helmut Prosch
Wieland Voigt $^{1}$
${ }^{1}$ Medical Innovations and Management, Steinbeis University Berlin, Berlin, Germany;
(Email: wieland.voigt@stw.de)
Helmut Prosch ${ }^{2}$
${ }^{2}$ Department of Biomedical Imaging and Image-guided Therapy,
Medical University of Vienna, Vienna, Austria.
(Email: belmut.prosch@meduniwien.ac.at)

Received: 25 June 2021; Accepted: 20 August 2021; Published: 30 October 2021. doi: $10.21037 /$ shc-2021-03

View this article at: https://dx.doi.org/10.21037/shc-2021-03

doi: $10.21037 /$ shc-2021-03

Cite this article as: Voigt W, Prosch H. Successful lung cancer screening more than just scanning persons at risk. Shanghai Chest 2021;5:34. 